\title{
Effect of ionic strength on phosphorus removal with modified sediments in lake: kinetics and equilibrium studies
}

\author{
Wei Huang, Binghui Zheng ${ }^{* *}$, Xia Jiang ${ }^{*}$
}

State Key Laboratory of Environmental Criteria and Risk Assessment, Chinese Research Academy of Environmental Sciences, Beijing, 100012, P.R. China

*E-mail: yixinghd6@163.com, jiangxia@craes.org.cn

** The author contribute equally to this article

doi: $10.20964 / 2016.12 .06$

Received: 22 August 2016 / Accepted: 29 September 2016 / Published: 10 November 2016

\begin{abstract}
Phosphorus concentration in lakes is difficult to lower without adding extra materials, and modified lake sediments have the greatest environment-friendly potential for phosphorus removal. In this study, sediment samples were collected from the outlet of Yangtze River (the world's third longest river) in the Eastern part of Dongting Lake (OS) and the river estuary into Dongting Lake (ES) and subsequently modified with iron. Phosphorus-removal efficiency in different ionic strengths of the sediment samples were evaluated, and phosphorus sorption kinetics and isotherms were analyzed using pseudo-first- or pseudo-second-order models and Langmuir or Freundlich models, respectively. Results indicated that the modified sediment samples (MOS and MES) had higher removal efficiency (74.9\%-89.2\% for MOS and 58.9\%-68.9\% for MES) for phosphorus than the raw sediment samples (26.0\%-34.3\% for OS and $13.9 \%-20.1 \%$ for ES) in different ionic strengths. The pseudo-second-order model $\left(R^{2}>0.95\right)$ better described the sorption kinetics than the pseudo-first-order one, and the sorption capacities of the sediment samples were highly influenced by ionic strength, with low ionic strength being favorable for phosphorus uptake. Modified Langmuir models well-described phosphorus sorption $\left(R^{2}=0.9049-0.9996\right)$. MOS and MES had higher maximum phosphorus uptake amounts (3.350 and $1.569 \mathrm{mg} \mathrm{g}^{-1}$, respectively) than the other modified phosphorus sorption materials and may thus be potential sorbents for the purification of wastewater containing phosphate.
\end{abstract}

Keywords: Sediment, Phosphorus, Sorption, Removal, Uptake amount

\section{$\underline{\text { FULL TEXT }}$}

(C) 2016 The Authors. Published by ESG (www.electrochemsci.org). This article is an open access article distributed under the terms and conditions of the Creative Commons Attribution license (http://creativecommons.org/licenses/by/4.0/). 